\title{
Castaneda vs. Jodorowsky: ¿un punto de vista similar sobre la magia en nuestro tiempo?
}

\author{
Irlanda Villegas ${ }^{\bullet}$ \\ Instituto de Investigaciones en Educación - \\ Universidad Veracruzana
}

\begin{abstract}
Resumen
Se exploran dos textos del último tercio del siglo XX, a saber, Viaje a Ixtlán. Las lecciones de don Juan (1972) de Carlos Castaneda y Psicomagia. Una terapia pánica (1995) de Alejandro Jodorowsky, cuya temática es el uso especializado de energía o "magia» como acto performativo de varias dimensiones: poético, teatral y onírico. Mediante el trazado de líneas comparativas, se presenta un análisis contrastivo de naturaleza antropológica-literaria de formas testimoniales-poéticas del discurso (bajo la forma de diario y entrevista), que pone de relieve el «decir» en tanto manifestación de "haceres». Se recurre al estudio de técnicas narratológicas contemporáneas, tales como la narración autobiográfica y la auto-narración disonante (Cohn, 1978) a fin de distinguir entre «sentir»e «intelectualizar». Se concluye que ambos textos cumplen una función conativa de propósitos didácticos con alcances éticos importantes en lo tocante a la responsabilidad que conllevan el desaprender y la toma de decisiones.
\end{abstract}

\section{Palabras clave:}

- prácticas discursivas como acto performativo-mágico · discurso testimonial · decir-hacer · autonarración disonante $\cdot$ sentir vs. intelectualizar

- Licenciada en Letras Inglesas, maestra en Literatura Comparada y doctora en Letras por la Universidad Nacional Autónoma de México. Traductora y docente. Autora de artículos de investigación y coordinadora editorial de ¿Qué es literatura comparada? Impresiones actuales y Acercamientos teóricos, Biblioteca Digital de Humanidades de la UV. 


\begin{abstract}
Herein two texts written between 1969 and 1999 are explored: Viaje a Ixtlán. Las lecciones de don Juan (1972) by Carlos Castaneda and Psicomagia. Una terapia pánica (1995) by Alejandro Jodorowsky where the main topic is a specialized use of energy or "magic» seen as a performative act of poetical, theatrical and oneiric dimensions. Comparatively, a contrastive analysis of testimonial and poetic forms of discourse (diary and interview), of anthropological and literary nature, in which "saying» is a manifestation of "savoir-faire» is presented. In order to discern «feeling» from «intellectualize», the use of contemporary narratological techniques, such as autobiographic narration and the dissonant self-narration (Cohn, 1978) is applied. As a conclusion, it is observed that these texts possess a conative function of didactic purposes that have an ethical scope, related to the degree of responsibility implied during (un)learning and decision-making activities.
\end{abstract}

\title{
Key words:
}

- Discursive practice as a performative-magic act · testimonial discourse - saying and savoir-faire - dissonant self-narration . feeling versus intellectualize

Castaneda y Jodorowsky son dos pensadores contemporáneos que se han interesado no sólo por poner en práctica algún tipo de magia sino también por explicarla. De ascendencia peruana, el antropólogo Carlos Castaneda (1925-1998), radicó en Los Ángeles y recogió sus experiencias sobre el aprendizaje del uso especializado de la energía que permite aprehender otras realidades o "brujería» a lo largo de nueve obras publicadas entre 1968 y $1998 .{ }^{1}$ Este autor ha despertado la curiosidad y el seguimiento tanto de los especialistas en la materia como de múltiples lectores debido a que fue creando paulatinamente un complejo sistema filosófico que comprende ciertas ideas sobre el pensamiento prehispánico. Por su parte, el chileno de ascendencia ucraniana, Alejandro Jodorowsky (1930), es escritor, dramaturgo, cineasta y especialista en Tarot. ${ }^{2}$ En las diversas facetas de su obra aplica el principio de lo que él mismo ha nombrado «el acto psicomágico», una forma de hacer que en lo cotidiano incida una forma más profunda de conocimiento. En 1972 apareció uno de los libros de Castaneda más atractivos por su contenido y por su presentación: Viaje a Ixtlán. Las lecciones de don Juan. Integrado por veinte capítulos, es posterior a Las enseñanzas de don Juan (1968) y Una realidad aparte (1971), en los cuales el autor asumía que su percepción del mundo había 
cambiado a raíz de la ingestión de psicotrópicos. Así pues, su intención al escribir el tercer libro fue rectificar esa idea y subrayar que "parar el mundo" es una condición para tener acceso a otro conocimiento. Poco más de diez años después, en 1993, Jodorowsky le concedió una entrevista a Gilles Farcet que resultó en un testimonio titulado Psicomagia. Una terapia pánica. Su publicación (1995) tuvo como propósito satisfacer la necesidad del autor de puntualizar cómo llegó a la psicomagia pasando por el acto poético, el acto teatral, el acto onírico y el mágico así como "proporcionar a las personas interesadas unas coordenadas, un texto que les sirviera de referencia». (Jodorowsky, 1995: 130)

Aunque las experiencias vertidas por estos autores difieren entre sí, es posible establecer algunos puntos de convergencia entre las dos obras mencionadas, siendo el principal que ambas aluden a la posibilidad de acceder a un tipo de conocimiento distinto del ordinario. Otro paralelismo notorio radica en el hecho de que ambos son aprendices que se convirtieron en maestros. Castaneda se inicia con don Juan, un brujo yaqui, mientras que Jodorowsky aprende técnicas de curación con Pachita, una bruja oaxaqueña. Cabe subrayar que el aprendizaje con Pachita sólo marca una pauta en la carrera de Jodorowsky como psicomago. Don Juan es, en cambio, la fuente principal, el nagual de Castaneda, razón por la cual toda su experiencia sensorial girará en torno las enseñanzas por él impartidas.

Vale la pena mencionar que, conforme a la herencia recibida desde el medievo, aunque tanto don Juan como Pachita sean descritos coloquialmente como «brujos», existe una diferencia crucial entre ambos. Don Juan posee un complejo sistema de conocimientos que es capaz de transmitir tanto en forma de ideas como de prácticas. Pachita, en cambio, sólo «instruye» a su aprendiz en la medida en que le permite fungir como su ayudante en las operaciones que realiza como curandera. Así pues, el nombre de "mago" puede ser aplicable a don Juan mientras que a su contraparte femenina, Pachita, le viene bien la etiqueta de «hechicera».

Es obvio que Jodorowsky conoce la filosofía expuesta por Castaneda. En Psicomagia, se refiere varias veces a aquél y afirma que en una ocasión coincidieron en la Ciudad de México y sostuvieron una conversación con extrañas consecuencias puesto que ambos enfermaron. Jodorowsky expresa su admiración por Castaneda y afirma que "su aportación ha sido inmensa ya que él creó una fuente de conocimiento diferente, la fuente sudamericana. Hizo revivir el concepto del guerrero espiritual (...) Volvió a poner de actualidad el trabajo sobre el sueño despierto» (1995:109). De ahí que no sorprenda encontrar algunas ideas afines en la obra de estos autores y se pueda especular sobre la influencia de uno sobre otro, aun cuando ambos afirmen haber llegado por muy distintas vías a conclusiones que, como lectores, nos puedan parecer similares.

Por consiguiente, un punto más de concordancia se da en algunas líneas temáticas desarrolladas por ambos autores, las mismas que ejemplificaré a lo largo de este texto: la toma de decisiones y el responsabilizarse por ellas; la necesidad de romper con la continuidad aprendida a fin de acceder a nuevas experiencias; en la batalla que representa el vivir, el enfrentamiento del adversario, mismo que se puede convertir en el aliado; el cobrar conciencia de que somos seres efímeros y que, por tanto, no nos podemos dar el lujo de desperdiciar el tiempo, y la realización de actos absurdos como vía para desarrollar las posibilidades de acceder a otras experiencias. No son éstos los únicos temas compartidos por los autores ${ }^{3}$ sino los que he seleccionado para el presente ensayo. 
En el aspecto formal — cómo están escritas las obras elegidas — se dan también algunas coincidencias que las hacen comparables. En ambos casos se trata de una narración autobiográfica, es decir, un relato en primera persona contado por el propio protagonista que, además, versa sobre su propia experiencia. El Viaje obedece a la forma de diario, mientras que Psicomagia es una entrevista. Ambas formas dan lugar al recuento de acciones ocurridas en el pasado contadas por su actor, en el presente.

Es pertinente aplicar aquí el término dissonant self-narration propuesto por Dorrit Cohn, que traduciré como «autonarración disonante», y que la teórica define como aquella narración en primera persona a través de la cual el narrador se refiere a un pasado propio que transcurrió bajo circunstancias de ignorancia y confusión (145), es decir, de poca claridad. La condición necesaria para que este tipo de narración se efectúe es la capacidad para recrear el pasado conforme se narra. A contraluz de una experiencia confusa ocurrida en el pasado, se da un proceso narrativo consciente, deliberado e intelectual. Cohn expone que este proceso narrativo funciona como la cognición retrospectiva de una experiencia interna que no puede reconocerse en el instante mismo en que ocurre. De este modo, se presenta una antinomia mental: en el terreno de lo sensorial —en el «sentir»— tiene lugar la experiencia propia, mientras que en el terreno de la inteligencia —en el «intelectualizar»— tiene lugar el acto de narrar.

Es de llamar la atención que la aparente contradicción que establece en su teoría Cohn, se ajusta perfectamente a la dicotomía expresada de modo explícito por Castaneda (y sugerida en Jodorowsky) entre los dos campos de conocimiento del hombre. El lado derecho es el de la conciencia normal, llamado «tonal» y corresponde al "primer anillo de poder», es decir, a la descripción del mundo que es compartida por todos los humanos. En cambio, el conocimiento del lado izquierdo es el de la conciencia acrecentada, llamado «nagual» y corresponde al «segundo anillo de poder» que se activa cuando se bloquea el funcionamiento del primero y que permite la percepción del mundo en término ajenos a su descripción ordinaria. El mundo cotidiano se percibe a través de la razón mientras que la «otra realidad» sólo puede percibirse evitando el uso de la razón. En varias de sus obras Castaneda señala que haciendo un acopio de energía le es dado recordar las enseñanzas a su tonal. ${ }^{4}$

Cabe entonces afirmar — sobre todo en el caso de Castaneda - que el recuento del aprendizaje del lado izquierdo constituye un acto de su lado derecho, es decir un acto consciente y deliberado. Si introducimos aquí el concepto «no hacer» es decir, la realización de cualquier tipo de acción que no sea congruente con la descripción cotidiana del mundo, podemos aventurarnos a afirmar que la experiencia propia relatada tanto en el Viaje a Ixtlán como en Psicomagia, constituye el no-hacer de Castaneda y Jodorowsky, en tanto que la narración que de ella llevan a cabo, representa un "hacer» ya que narrar, escribir, son acciones que emanan y, a su vez, revalidan la descripción ordinaria del mundo.

Pero ¿cómo, si no de esta manera, hacer llegar a un amplio público de lectores las enseñanzas adquiridas? Afirmo que ambos textos persiguen un propósito didáctico y cumplen una función conativa, en términos de Jakobson. ${ }^{5} \mathrm{~A}$ fin de convencernos y así, transmitir el conocimiento adquirido, ambos narradores se valen de anécdotas, relatos breves de algo que sí sucedió. Muy a menudo, estos simples relatos cobran la estatura de parábolas, narraciones simbólicas de las cuales se desprende una enseñanza moral. Aquí entra en juego la confiabilidad de los 
narradores. En ese papel, no pocas veces Castaneda y Jodorowsky funcionan como filtros mediante los cuales recibimos las ideas de otros personajes como don Juan o Pachita. Recurren, entonces, a manejos verbales propicios para convencer, así como a la inserción de diálogos en la narración cuyo efecto es dotar de vivacidad e inmediatez el relato de lo sucedido hace tiempo.

\section{Tomar decisiones y responsabilizarse por ellas}

Ésta es la enseñanza que se desprende de sendas anécdotas relatadas por Castaneda y Jodorowsky que tratan sobre una relación filial. En el capítulo V del Viaje a Ixtlán, «Hacerse responsable», Castaneda se queja con don Juan de que su padre prometía ir a nadar a las seis de la mañana durante las vacaciones y nunca lo cumplía. Da inicio a su relato diciendo: «Le narré [a don Juan] la historia de mi padre, que solía lanzarme interminables sermones sobre las maravillas de mente sana en cuerpo sano» (Castaneda, 1975:72) de modo que a nosotros como lectores nos cuenta algo que le contó a don Juan. La distancia entre la narración y lo narrado es pues, doble. Se nota también cierta grandilocuencia que acusa una actitud crítica del hijo hacia el padre. Éstas son características de la autonarración disonante. Para dar veracidad a su relato, Castaneda cita a su padre:

Yo incluso había memorizado el monólogo subsiguiente:

- Hum... un poco nublado hoy. Mira, voy a acostarme otros cinco minutos, ¿eh?

¡No más de cinco! Sólo voy a estirar los músculos y a despertar del todo. Invariablemente se quedaba dormido hasta las diez, a veces hasta mediodía (Castaneda, 1975:70-71).

El uso del pluscuamperfecto ("había memorizado») señala anterioridad con respecto a un hecho pasado, lo que nos aleja nuevamente de la anécdota en sí, que tuvo lugar durante la niñez de Castaneda y que está siendo narrada por el adulto a don Juan. Ya para entonces ha habido una toma de conciencia y Castaneda supone comprender muy bien lo sucedido; por eso es capaz de expresar acciones pretéritas que se repetían. El pasado imperfecto «se quedaba dormido» acompañado por el adverbio «invariablemente» denota la repetición de un hecho en el pasado sin importar su inicio o su fin. Sin embargo, el propio narrador está consciente de que cita el monólogo de su padre. Su efecto es transportarnos hasta la infancia de Carlos.

Enseguida, Castaneda da cuenta de la reacción de don Juan a su historia y, para ello, cita el diálogo que tuvo lugar entre ellos. En este momento, el narrador acorta la distancia entre lo narrado (la vez que le contó a don Juan la historia de su padre) y la narración. Aquí también estamos frente a una autonarración disonante, como lo comprueba la siguiente reflexión ante la reprimenda de don Juan: «Sus palabras, llenas de fuerza devastadora, resonaron en mi mente. Derribó todas mis defensas. No podía yo discutir con él. Tomé refugio en la escritura de mis notas» (Castaneda, 1975: 73). Castaneda emite un juicio claro sobre los sentimientos que don Juan le provocó en ese momento. 
En Psicomagia, Jodorowsky relata dos actos paralelos donde los actores son él mismo y su hijo Brontis. El primero tiene lugar en el desierto cuando el niño cumple siete años y llega a vivir con su padre (en realidad es la primera escena de la película El topo). El segundo ocurre un día lluvioso en Vincennes, Francia, cuando Brontis cumple 24 años. En ambos aparecen tres símbolos: (1) un oso de peluche, primero relleno de paja (que Jodorowsky regaló a Brontis al nacer) y, trece años más tarde, otro oso suave y flexible que intenta sustituir al primero; (2) una foto de Bernadette - la madre - primero en blanco y negro y luego a color, y (3) una sombrilla negra, antes, y un paraguas negro después. En ambos actos hay una enunciación imperativa del padre hacia el hijo que funciona como conjuro y que Jodorowsky autocita:

1. «Ya tienes siete años, eres un hombre. Entierra tu primer juguete y el retrato de tu madre» (tomado, a su vez, del guión de El topo) (Jodorowsky, 1995:144).

2. «Hoy cumples siete años y tienes derecho a ser niño. Ven a desenterrar tu primer juguete y el retrato de tu madre» (cita del vigésimo cuarto cumpleaños de Brontis) (145).

Las citas textuales insertas en la narración dan al relato la ilusión de una cercanía entre el lector y los hechos. Sin embargo, en varias ocasiones, Jodorowsky da prueba de ser un narrador consciente y crítico del Jodorowsky de aquel momento, como cuando alude a su esterilidad y dice «en mi destino no estaba inscrita la procreación» o cuando justifica su decisión de volver a ver a su hijo: «experimenté una crisis de conciencia». Más aún, su narración filial presenta una larga digresión acerca de su relación de pareja con Bernadette que rompe la cronología. Jodorowsky hace ejercitar a su hijo el entierro/desentierro de su infancia como actos psicomágicos, es decir, actos simbólicos capaces de provocar un efecto en la realidad ordinaria. El segundo acto, sin embargo, pretende y logra ser un acto psicomágico «reparador». La brusca separación de la infancia y de la madre promovida por el padre se soluciona diecisiete años después con el rescate de ambos elementos y la consecuente reconciliación entre el padre y el hijo.

En el relato de Castaneda también se restaura el orden filial, gracias a don Juan. El niño Carlos recupera a su padre encarnado en el viejo brujo. Éste lo reprende por haber sido incapaz de comprender a su padre pero no sin reconstituir el vacío del cual se lamenta:

- Tú habrías podido tener un gesto con tu padre nadando en su lugar, pero no lo hiciste, a lo mejor porque eras demasiado joven. Yo he vivido más que tú. No tengo nada pendiente. No hay ninguna prisa en mi vida, por eso puedo tener contigo un gesto como es debido (Castaneda, 1975:74).

El gesto de don Juan corresponde al acto reparador de Jodorowsky. 


\section{Para el mundo. La muerte como consejera \\ Dead Can Dance}

Hay otras dos historias contadas por estos autores entre las cuales es posible tender puentes. Me atrevería a llamarlas parábolas, debido a que en ambas hay un fuerte carga simbólica. En la introducción al Viaje a Ixtlán, Castaneda refiere a don Juan, en primera instancia, y al lector, en segunda, la historia de un niño, hijo de un amigo suyo que se porta muy mal. La separación de sus padres parece ser la causa de su indisciplina e inadaptabilidad. El narrador comienza así: "Le conté el dilema de un amigo mío con su hijo de nueve años» (Castaneda, 1975:10-13). Como puede apreciarse, la distancia entre la narración y lo narrado es otra vez doble. El maestro da al alumno una serie de instrucciones que éste, a su vez, tendrá que dar a su amigo. El narrador lo parafrasea:

Don Juan delineó entonces una extraña estrategia. Yo debía instruir a mi amigo para que hiciera que el hombre lo siguiese o lo esperara en un sitio a donde fuera a ir con su hijo. El hombre, en respuesta a una seńa convenida, dada después de cualquier comportamiento objetable por parte del pequeño, debía saltar de algún escondite, agarrar al niño y darle una soberana tunda (Castaneda, 1975:12-13).

Pero el narrador también inserta el diálogo que tiene lugar entre don Juan y él a raíz de esta historia. Esta inserción da al relato velocidad y frescura y, puesto que escuchamos la mismísima voz de don Juan — cumpliendo una función conativa-, lo dota de verosimilitud:

«Cuando el niño esté más contenido, debes decir a tu amigo que haga una última cosa por él. Debe hallar el modo de dar con un niño muerto, quizá en un hospital o en el consultorio de un doctor. Debe llevar allí a su hijo y enseñarle el niño muerto. Debe hacerlo tocar el cadáver una vez más, con la mano izquierda, en cualquier lugar menos en la barriga. Cuando el niño haga eso, quedará renovado. El mundo nunca será ya el mismo para él.» (13)

Las comillas son de Castaneda y las usa para citar a don Juan. Nótese que la enseñanza es para el lado izquierdo (el niño vivo debe tocar al muerto con su mano izquierda), o sea, que se inscribe en un no-hacer. En Psicomagia Jodorowsky presenta una anécdota similar: junto con sus amigos universitarios consiguen el brazo de un cadáver, lo esconden en la manga de sus abrigos y saludan con él a varias personas, quienes no se atreven a decir que la mano esté fría o a externar algún otro comentario. La autonarración disonante es muy clara en este ejemplo:

La poesía es convulsión, como un terremoto. Denuncia las apariencias, desenmascara la falsedad y cuestiona los convencionalismos. Recuerdo que una vez fuimos a la Facultad de Medicina y, con la complicidad de mis amigos estudiantes, robamos el brazo de un cadáver. (Jodorowsky, 1995:26-27)

Primero, Jodorowsky enuncia una verdad de la cual está plenamente convencido en el presente - la poesía puede trascender hasta convertirse en un «acto» y 
un acto es capaz de modificar nuestra percepción de la realidad, aun cuando no lo queramos reconocer-y, luego, la ejemplifica con una anécdota ocurrida en el pasado. Son los propios narradores quienes sugieren que éstas no son simples anécdotas. Desde su claridad en el presente, Castaneda afirma:

Me di cuenta entonces de que, a través de los años de nuestra relación, don Juan había estado usando conmigo, aunque en una escala diferente, la misma táctica que sugería para el hijo de mi amigo. Le pregunté al respecto. Dijo que todo el tiempo había estado tratando de enseñarme a «parar el mundo». (1975:13)

Por su parte, Jodorowsky expresa —en términos actuales - un aprendizaje obtenido en el pasado: «El acto creaba otra realidad en el seno de la realidad ordinaria. Nos permitía trascender a otro plano, y aún hoy estoy convencido de que, con actos nuevos, se abre la puerta de una dimensión nueva» (27). Así pues, de simples anécdotas que comparten algunos elementos comunes se deprenden enseñanzas similares: crear otra realidad en el seno de la realidad ordinaria. Con ello se crean las condiciones para acceder al segundo anillo de poder. Como ocurre en las parábolas, los narradores presentan su historia y proceden a extraer y hacer explícita la enseñanza encerrada en ella.

\section{El absurdo como vía de acceso a una realidad aparte}

Some of us are saints

Some are clowns

Just like me they're falling down.

TEARS For FEARS

Contrariamente al lado derecho, que reacciona ante ideas, el lado izquierdo entiende mejor los mensajes que le son transmitidos por otras vías, como pueden ser los actos. Este lenguaje no tiene que circunscribirse ni a un ejercicio mental y ni siquiera a la imaginación. Es menester que se concrete en actos. Sin llamarlo así, Castaneda da cuenta de un «acto mágico» en el capítulo titulado "El anillo de poder del brujo» (XVIII), mientras que Jodorowsky denomina a una acción deliberada con un propósito específico "acto poético». Se establece, de este modo, un paralelismo entre la magia y la poesía, como vías de acceso a una realidad distinta a la ordinaria. Las anécdotas son simples. El auto de Castaneda desaparece y don Juan y un amigo brujo suyo lo hacen aparecer (1975:319-337). Por su parte, Jodorowsky decide caminar en línea recta con su amigo poeta Lihn, pase lo que pase (1995:21-23). En ambos casos, se rompe el binomio que predomina a lo largo de cada libro (Castaneda-don Juan/ Farcet-Jodorowsky). Digo que estos actos son ridículos porque se busca un automóvil 
debajo de piedritas y porque, con tal de no desviar el paso, se trepa a un árbol o se entra a una casa ajena. Además, hay sendos retos: que aparezca el carro de Castaneda y que no se rompa la línea recta. Para enfrentarlos, se exige la realización de un acto concreto, es decir, no basta la imaginación: al final vemos la aparición del automóvil y sabemos que los amigos caminaron en línea recta.

El acto poético de Jodorows $\mathrm{ky}^{6}$ no se contenta con escribir ni leer poesía, sino que tiene que desembocar en hacer poesía con el cuerpo: caminar en tal o cual forma, durante cierto tiempo, con un propósito determinado.

Gilles: ¿En qué consistían esos actos [los poéticos]?

Jodorowsky: Por ejemplo, un día Lihn y yo decidimos andar siempre en línea recta, sin desviarnos para nada. Por ejemplo, si en un paseo nos encontrábamos delante de un árbol, en lugar de rodearlo, trepábamos a él y, una vez arriba, continuábamos la conversación. O, si en nuestro camino había un coche, nos encaramábamos a él y caminábamos por el techo (...) Frente a una casa, llamábamos al timbre, entrábamos por la puerta y salíamos por donde podíamos, a veces, por una ventana. Lo importante era seguir la línea recta sin prestar atención al obstáculo, hacer como si no existiera. (Jodorowsky, 1995:22-23)

En esta narración se recurre al uso del pretérito imperfecto porque la acción pasada que se expresa interesa sólo en su duración: es un pasado iterativo. El brujo mazateco Genaro no hace gala de sus habilidades desde un estrado con la ayuda de una varita mágica para desaparecer y luego aparecer el auto de Castaneda. Se revuelca, se arrastra, se trepa, hace magia con su cuerpo: ${ }^{7}$ se rueda por el suelo; «nada» en el piso; camina "con una especie de rebote», con "pasos más largos que de costumbre»; mueve las manos "como si azotaran o batiera objetos invisibles»; aúlla como coyote; se para de puntas, arquea la espalda, estira los brazos por encima de la cabeza «semejando con sus dedos una garra»; se abalanza sobre una rama; se acuesta bocabajo descansando la barbilla sobre las manos entrelazadas... todo ello hasta que, nos cuenta el narrador:

De pronto, don Genaro hizo un amplio movimiento con la diestra y asió algo. Se puso en pie apresuradamente, y lo mismo don Juan. Don Genaro nos mostró la mano cerrada y nos hizo seña de ir a mirar. Cuando la tuvo extendida, un gran objeto negro salió volando. El movimiento fue tan súbito, y el objeto volador tan grande, que salté hacia atrás y estuve a punto de perder el equilibrio. (Castaneda, 1995:333)

Enseguida, don Genaro construye un papalote con su sombrero y lo hace volar, éste cae y aparece el carro buscado. La magia está consumada. Sin embargo, el acto insulta el sentido común de Castaneda quien, como aprendiz experimenta diversos estados de ánimo que van de la ira a la vergüenza y, como narrador disonante instalado en el presente que se niega a entender el lenguaje dirigido a su lado izquierdo, expresa ampliamente sus contrariedades: «Pensé en la imposibilidad de aquello que estaba ocurriendo; era algo inconcebible según el orden lógico por el cual juzgo habitualmente el mundo frente a mí» (Castaneda, 1975:333). Intuye que es presa de la burla de los brujos quienes «bromean», "ríen inconteniblemente», «tienen espasmos de risa», "patalean», «se carcajean», «chasquean la lengua», "payasean», 
según el propio Castaneda. Como buen narrador disonante, a la descripción de estas acciones opone términos como: «cosas absurdas» o «incoherencia».

Don Genaro y don Juan, Jodorowsky y Linh son presentados como una especie de «bufones» — actores que hacen reír- a través de la autonarración disonante. Sin embargo, como el Feste de Shakespeare en Noche de Epifania, estos personajes «han sido traspasados por el aspecto oscuro de la vida». ${ }^{8}$ Deciden reír puesto que saben que su tiempo es corto y la muerte su cazadora. A través de la narración, se pone énfasis en la disociación existente entre la razón y el estado de conciencia alterado del narrador. Él mismo apunta que durante este episodio, en repetidas ocasiones, don Juan o don Genaro golpearon su espalda lo que equivale a «mover su punto de encaje», es decir, prepararlo para "ver».

Más allá de que la descripción de estos actos sea divertida e interesante, su valor intrínseco radica en su efecto. Estos actos transgreden la lógica común, la realidad ordinaria y, por tanto, le hablan al lado izquierdo del ser humano, invitándolo a crear y a acceder a otra realidad

\title{
¿Adversarios o aliados?
}

\author{
Apuesto que será la primera vez que alguien
}

derriba a un aliado a cuadernazos.

DON JuAN acerca de CARlos

A medida que se entrena el lado izquierdo, cede la razón y se comienza a penetrar en mundos desconocidos. La vida del mago no es sino esta travesía. Puede ser solitaria y, de cierto, presenta fases de nostalgia, pero promete el conocimiento de una realidad más rica que la que hemos construido como humanidad. El camino del conocimiento es duro. En él hay peligros, tristeza y frustración. Dos relatos de Castaneda y Jodorowsky, respectivamente, aluden a ello.

En las páginas 42 a 44 de Psicomagia, el autonarrador disonante lee a Farcet un sueño lúcido que anotó en su cuaderno amarillo en 1970. Se recurre al presente iterativo o gnómico tanto para dar durabilidad al relato referido como para expresar «verdades eternas» (Cohn, 1978:190):

Estoy solo en una casa desconocida. Todo me parece completamente real pero, sin saber por qué, ya que nada me lo indica, me digo: «Quizá estoy soñando, puedo volar; vamos a ver» Hago un esfuerzo, me apoyo en el aire con las palmas de las manos, y me lanzo hacia las alturas. Floto en la habitación. «iEs un sueño!», me digo. Decido aprovechar la experiencia para volar bien, no ya verme volar sino sentirme volar. Doy una vuelta de campana, subo y bajo. Estoy satisfecho. Decido planear por toda la casa. (Jodorowsky, 1995:43) (comillas y cursivas del autor)

Desde un presente de mucha mayor claridad (la vigilia), el narrador cita su propio monólogo 9 sostenido durante el sueño. Llama la atención las acciones realizadas en el sueño - volar, flotar - que, como en el apartado anterior, son corporales más que mentales porque están nutriendo el lado izquierdo del conocimiento. 
Más aún, debido a que al realizar estas acciones el narrador transgrede la ley de la gravedad y a que se trata de un sueño, estamos ante un estado de conciencia alterado. Una vez alcanzado ese estado, el soñante encuentra a sus aliados como lo expresa la continuación de la cita anterior:

Voy por un pasillo y llego a un salón oscuro. En un rincón veo a dos niños de unos cinco años. Avanzo hacia ellos para verlos mejor: no son niños sino dos gnomos viejos, delgaditos y arrugados. Se ríen y se esconden. Son los espíritus de la casa. Tienen un aire inquietante. Me esquivan. Desaparecen entre las sombras y se burlan de mí. No me atrevo a buscarlos. (Jodorowsky, 1995:44)

Al interpretar su propio sueño en el cuaderno amarillo, Jodorowsky admite que debió buscar la alianza con esos gnomos, quienes quizá le hubieran ayudado a encontrar a su dios interior.

«Debí perseguir a los gnomos, hacerles frente, hablarles sin dejarme turbar por sus burlas, entrar en relación con ellos, conocer sus secretos. Debí crear mundos, atravesar la muerte, llegar al centro de mi ser, vencer monstruos y terrores (...) Espero que la próxima vez me muestre más audaz y domine el miedo. También tengo que encontrar aliados y aceptarlos, no hacer siempre todo el trabajo yo sólo». (1995:44) (comillas de Jodorowsky, cursivas mías)

Como en la psicología jungiana, es necesario que el ser humano encare su sombra, su lado oscuro a fin de conocerse plenamente, de reconocer a su dios interno que no es otro, como afirma el propio Jodorowsky en Psicomagia, que él mismo. ${ }^{10}$ Pero el concepto de «aliado» ha sido, sin lugar a dudas, mucho más desarrollado por Castaneda que por Jodorowsky. En el último capítulo de la obra que nos ocupa, Genaro relata su travesía hacia ese otro conocimiento; para que ésta pueda dar inicio, fue menester que se enfrentara a su aliado. Una vez más, este enfrentamiento es de carácter práctico y no intelectual. Genaro ha de agarrarse a trancazos con el aliado aun cuando éste ni siquiera sea humano. El resultado es un gozo inexplicable.

Después que lo agarré, empezamos a dar vueltas. El aliado me hizo dar vueltas, pero yo no lo solté. Giramos por el aire tan rápido y tan fuerte que yo ya no veía nada. Todo era como una nube. Dimos vueltas, y vueltas, y más vueltas. De repente sentí que estaba parado otra vez en el suelo. Me miré. El aliado no me había matado. Estaba yo entero. ¡Era yo mismo! Supe entonces que había triunfado. Por fin tenía un aliado. Me puse a saltar de alegría. ¡Qué sensación! ¡Qué sensación aquélla! (Castaneda, 1975:156)

La lucha cobra mucho sentido puesto que, a partir de que don Genaro vence, la entidad adversaria se convierte en un compañero permanente. Aparecerán progresivamente candidatos a ser amigos que, gracias al aliado, Genaro podrá identificar como distractores, oponentes — en suma, adversarios-, a que él cumpla su destino de brujo. Después de la batalla con el adversario, oímos narrar a don Genaro, pierde el sentido de la ubicación (su conciencia está alterada, «acrecentada», dirá Castaneda) y emprende una jornada concreta hacia su lugar de origen, Ixtlán, en primera instancia y, en segunda, una jornada interminable hacia lo desconocido. En su camino aparecen indios, mujeres, vendedores, pastorcitos, todos ellos aparentemente normales, pero don Genaro se da cuenta de que son «otra cosa» por el tono 
de sus voces y la ansiedad de llevárselos consigo: «Seguí andando. Supe entonces que iba bien para Ixtlán y que esos fantasmas trataban de apartarme de mi camino».

Al igual que Jodorowsky, Castaneda hace citar a su personaje su propio monólogo. Tenemos así una doble distancia: Castaneda hace hablar a Genaro, quien nos narra una experiencia suya ya interpretada. Las interrupciones del propio Castaneda en este relato, así como el diálogo entre don Juan, don Genaro y él mismo, acercan un poco el enfoque de lo narrado al momento de la narración. El viaje de Genaro ocurrió hace mucho tiempo. Hace tiempo también (pero no tanto) les contó a don Juan y a Carlos de su viaje. Y ahora Carlos nos cuenta a nosotros. Ésta es claramente una autonarración disonante enriquecida con la inserción de técnicas narrativas diferentes.

\section{Los resultados}

Nunca llegaré a Ixtlán.

Don Genaro

A través de los ejemplos presentados nos hemos asomado a dos aprendices de magia que narran su autobiografía con el propósito de que los lectores sepamos de sus experiencias y apliquemos sus enseńanzas a nuestra propia vida. La técnica narrativa básica utilizada por ambos es la autonarración disonante, es decir, aquella narración en el presente donde lo narrado es la propia experiencia del narrador. La principal diferencia entre el presente y el pasado radica en la construcción de una distancia entre lo narrado y la narración. Entre esos dos momentos ha tenido lugar el desarrollo de una lucidez. Dado que el principal recurso para compartir con nosotros esas experiencias es su propia memoria, como lectores, podemos optar o no por confiar en la veracidad de lo que nos cuentan. Como narradores, recurren a la inserción de diálogos, de autocitas, de notas escritas por ellos mismos en forma de diario que dotan de viveza y frescura la narración. Las experiencias relatadas poseen, como hemos visto, algunos elementos temáticos entre los cuales es posible trazar líneas de comparación. A mi modo de ver, Castaneda presenta una mayor complejidad temática que se refleja en la complejidad narrativa. Estoy convencida de que — quizá sin proponérselo- su obra representa un intento de construir un vasto sistema filosófico. Existe congruencia entre las ideas presentadas en sus distintas obras, aun cuando todas giran en torno a la misma experiencia: su aprendizaje de la brujería.

Las experiencias referidas tanto por Jodorowsky como por Castaneda violentan la lógica común y pudiera afirmarse que son del orden extrasensorial. Ambas traen de comunicar a los lectores una experiencia que no es racional a través de un método racional: la escritura. Hay una intención clara de divulgar una forma de conocimiento distinta a la ordinaria. Queda entonces en el aire la pregunta: ¿ Es la 
obra escrita por Castaneda un «hacer» o un «no-hacer»? Recordemos que la naturaleza básica que tuvo el antropólogo (su «vicio», diría don Juan) era tomar notas. Basándose en ellas nos hizo llegar su experiencia. En este sentido, su autonarración sería un «hacer». Pero, el tratar de recordar lo sucedido (lo narrado) durante estados acrecentados de la conciencia bien puede constituir un ejercicio completamente ajeno al que sí estaba acostumbrado: el intelectual. Estaría entonces frente a un «no-hacer» de Castaneda. El caso de Jodorowsky es más fácil de discernir. Hay una clara necesidad de comunicar las experiencias personales y quizá, la publicación de Psicomagia pretenda ser un "acto poético», es decir, una actividad que ponga en marcha las ideas sobre la adquisición de otro tipo de conocimiento distinto del ordinario. Es muy probable, aunque su discusión rebasa los límites del presente texto, que este objetivo se logre con mayor eficacia en sus obras cinematográficas que, aunque autorreferenciales, se centran menos en su propia personalidad.

\section{Notas}

${ }^{1}$ Las obras escritas por Castaneda son: Las enseñanzas de don Juan (1968), Una realidad aparte (1971), Viaje a Ixtlán (1972), Relatos de poder (1974), El segundo anillo de poder (1977), El don del águila (1981), El fuego interno (1984), El conocimiento silencioso (1987) y Pases mágicos. La sabiduría de los chamanes del antiguo México: la tensegridad (1998).

${ }^{2}$ Entre sus principales realizaciones cinematográficas destacan Fando y Lis, El topo, La montaña sagrada y Santa Sangre, mientras que figura su labor en cómics con Fábulas pánicas. Su última novela fue Albina y los hombres-perro (2000), aunque su producción ha continuado con ensayos y poesía

${ }^{3}$ El tema del ensueño, o sueño lúcido es, quizá, el punto en común más obvio que, sin embargo dejo de lado ya que no se aborda en el Viaje a Ixtlán, objeto de este análisis.

${ }^{4}$ Cfr. G. Marín, Para leer a Carlos Castaneda, 1996 y Víctor Sánchez, Las enseñanzas de don Carlos, 1987.

5 «Orientada hacia el destinatario, halla a su más pura expresión gramatical en el vocativo y el imperativo». Jakobson (1984:355).

${ }^{6}$ Está basado en el postulado del Futurismo italiano que afirma que la poesía es acción.

${ }^{7}$ Aun cuando Castaneda no lo hace explícito, quizá porque al momento de la escritura del Viaje no lo tiene claro o simplemente porque no quiere poner énfasis en ello, sí describe los «pases brujos» realizados por Genaro.

${ }^{8}$ Comentario de Federico Patán en el Prólogo a Noche de Epifanía, Nuestros Clásicos, UNAM.

${ }^{9}$ Cohn le llama a esta técnica self-quoted monologue.

${ }^{10}$ En un sueño donde se propone descubrir a su maestro interior, convocando a la divinidad, aparece Jodorowsky mismo al centro de un escenario (1995:59-60). 


\section{Bibliografía}

Castaneda, C. ([1972] 1975). Viaje a Ixtlán. Las lecciones de don Juan. (Traducción al español de Juan Tovar). México: Fondo de Cultura Económica.

Cinn, D. (1978). Transparent Minds. Narrative Modes for Presenting Consciousness in Fiction. Nueva Jersey: Princeton University Press.

Jаковson, R. (1984). Ensayos de lingüistica general. (Traducción al español de Pujol y Cabanes). Barcelona: Ariel.

Jodorowsky, A. y Farcet, G. (1995). Psicomagia. Una terapia pánica. (Traducción al español de Ana Ma. de la Fuente). México: Seix Barral. Marín, G. (1996). Para leer a Carlos Castaneda. México: Colofón.

SÁnChez, V. (1987). Las enseñanzas de don Carlos. Aplicaciones prácticas de la obra de Carlos Castaneda. México: Norma.

\section{Villegas, Irlanda}

«Castaneda vs. Jodorowsky: ¿un punto de vista similar 